\title{
Characteristics of interdisciplinary research in author keywords appearing in Korean journals
}

\author{
Sunyoung Kwon \\ Department of Library and Information Science, \\ University of Hannam, Daejun, KOREA \\ e-mail: sykw@hnu.kr
}

\begin{abstract}
Keywords for academic papers are terms selected and created by the authors, and are, in general, considered a core element that summarizes and represents the papers' content. This research analysed the ways in which the author keywords for academic papers are used in multiple disciplines. The Brillouin index was used for an analysis of interdisciplinarity. As a result, 63.7 percent of the keywords were shown to appear in only one area of study. These cannot be considered keywords with interdisciplinarity, but rather with topic specificity. In addition, the interdisciplinarity degree of 80 percent of the keywords were low, between 0 and 0.499. This indicates that the majority of author keywords for academic papers do not show interdisciplinarity. Meanwhile, certain author keywords had a fairly high interdisciplinarity degree. In this case, they can be seen as topics that are researched in multiple disciplines. It was revealed that the interdisciplinarity degree of author keywords in art/physical education are lower than in the humanities or social sciences. This suggests that the interdisciplinarity of author keywords is lower in art/physical education than in the humanities or social sciences.
\end{abstract}

Keywords: Interdisciplinarity; Interdisciplinarity degree; Author keywords; Academic papers; Brillouin index

\section{INTRODUCTION}

Generally, author keywords in academic papers can be considered as a key element to understand the contents of the paper. Researchers use the phrase author keyword interchangeably with other phrases, such as 'author-keyword', 'author-assigned keywords', 'keyword given by author'; it, however, is commonly defined as 'a term selected by the author of an academic paper and given to the paper in person' (Hartley and Kostoff 2003; Gil-Leiva and Alonso-Arroyo 2007; Strader 2009; Liu and Zhang 2010; Haisheng 2012; Weijing and Ying 2013; Kwon 2014; Lu and Kipp 2014). Because author keywords summarize and represent the topic of a research paper, researchers tend to carefully select terms that are consider the most essential and important in the paper. The reasons for this are that: (a) research colleagues can select papers by rapidly checking author keywords, as they are aware that the author keywords consist of the most essential terms that represent papers; and (b) they can verify related keywords previously unknown to them and use them to expend their searches. In other words, as author keywords for an academic paper facilitate search and classification without accessing its entire content, they can be seen not only as a formal element for paper submission, but also as an essential element for information search. Author keywords also can be used to assist accessing a paper through subject classification as well as word search (Lewison and Cunningham 1991). Surely, the use of controlled vocabularies, such as Medical Subject Headings (MeSH), should be considered for the optimum result. However, MeSH is limited to medical sciences and not used in other 
fields. In other words, researchers rarely use a controlled vocabulary when selecting author keywords outside of the medical sciences field. If they were to do so, would it be impossible to represent a topic through author keywords selected from uncontrolled vocabularies rather than controlled ones? When it is assumed, as mentioned earlier, that author keywords among the 'elements based on which users select papers' are important, researchers are likely to intentionally select important, frequently used, and essential keywords in their research fields. In the cases where keywords are extracted from only a few papers, their appearance frequencies are low; hence, which terms are the essential keywords in that specific field would be unknown. However, if the appearance frequencies of author keywords extracted from relatively many papers are analysed, what the essential keywords in the relevant field are would certainly be revealed, and these keywords could be regarded as representing the field. In other words, the author keywords that appear repeatedly in research papers in a specific field can be defined as the major keywords of the field and assumed to suggest its topics.

While some terms appear only in specific fields, others appear across multiple fields. Clearly, the latter case is rare among author keywords for academic papers in a traditional single discipline. It is due to the increase of interdisciplinary literature (Braun and Schubert 2003). which is unlike in the past. Today, the quantity of information and knowledge is increasing more dramatically than ever, and technology advancement and the complexity of social structures are also accelerating. It is, in fact, almost impossible to understand the current society through the scope of traditional single disciplines. To understand contemporary society and address its problems, researchers in each field sometimes apply research methods or theories in collaboration with researchers in other fields through multiple manners of interaction. This trend sometimes results in an outcome that can be newly applied or regarded as the movement of a convergence study or interdisciplinary research. As interdisciplinary research increased, there emerged a need for researching the characteristics and impact of interdisciplinarity in each discipline, for research on interdisciplinary structure makes possible research development, stream, tendency, and prediction (Pfirman and Martin 2010).

Interdisciplinary information can be obtained through an analysis of the co-authors or topics of papers, citations across literature, simultaneous citation analysis, and an analysis of topic words given to papers (Pfirman and Martin 2010). In South Korea, research on interdisciplinarity through citation analysis has been done in only some disciplines thus far (Chung 2012; Park and Jung 2013). In comparison, this research did not limit its target to those disciplines but expanded it to academic papers in the fields of the humanities, social sciences, and art/physical education. In this case, of course, an analysis can be challenging, especially when a method such as citation analysis is used, due to the massive amount of data. Therefore, while expanding the range of disciplines, this research measures the interdisciplinarity of disciplines not through citation analysis, but through the appearance frequencies of author keywords in each discipline. Although this method is different from the traditional methods for measuring interdisciplinarity, it is based on the premise that the author keywords of each paper that discusses a specific topic or problem can represent diverse disciplines or topic areas. In other words, if specific author keywords are used in multiple disciplines, they can also be examined from an interdisciplinary perspective.

Thus far, research conducted in relation to interdisciplinarity has generally focused on specific disciplines, and research papers or works of literature have been the unit of analysis in most cases. This research, however, differs for two reasons. First, the research scope was not limited to a specific discipline but accessed from the perspective of a hierarchical classification of studies. In other words, it did not focus on examining a specific discipline in 
relation to other disciplines, but it rather undertook a more macroscopic approach. Second, the unit of analysis was neither research papers nor literature; it was author keywords for academic papers.

In particular, no research has been done on how author keywords for academic papers are used in diverse disciplines. A systematic study is necessary to empirically examine this question. According to the National Research Foundation of Korea, disciplines are classified by and large into 'humanities', 'social sciences', 'natural sciences', 'engineering', 'medical and pharmaceutical science', 'agriculture, fisheries, and oceans', 'art/physical education', and 'complex studies'. This research limits its scope to 'humanities', 'social sciences', and 'art/physical education' and measured interdisciplinarity through author keywords for academic papers in these fields.

The terms used in this paper are author keywords for academic papers. Characteristically, they reflect the topic of the paper they are attached to. Depending on the nature of each term, some reflect the features of a specific discipline and appear only in that discipline, whereas others appear across multiple disciplines. This is defined as 'the interdisciplinarity of author keywords' in this research. The analyses were conducted based on the Brillouin index, which was used in previous research measuring the interdisciplinarity of different disciplines (Steele and Stier 2000; Tang 2004; Huang and Chang 2011; Chang and Huang 2012). In this research, the following questions are examined:

a) What are the terms with a high interdisciplinary degree in each of the fields of humanities, social sciences, and art/physical education?

b) What are average of interdisciplinarity degree in each sub-discipline?

c) How are the degree of interdisciplinarity distributed? How do the distributions of the humanities, social sciences, and art/physical education fields differ from one another?

\section{LITERATURE REVIEW}

\section{Interdisciplinarity of Journals}

Since author keywords for academic papers are closely related to their topics, it is assumed that they are related to the research that assessed the interdisciplinarity of such papers. The reason for this is that, to determine the interdisciplinarity of a paper, the indices of various topics associated with the paper are calculated (Huang and Chang 2011; Chang and Huang 2012). the author keywords for the paper are also subject to the topics of the field that the paper belongs to.

Interdisciplinarity refers to connections among multiple disciplines. Traditionally, interdisciplinarity has often been verified through an examination of reference citations. As interdisciplinary research has increased over the years, however, various ways of measuring interdisciplinarity are being used (Herring 1999; Steele \& Stier 2000; Leydesdorff 2007; Sugimoto 2009; Obermeier and Brauckmann 2010; Lariviere and Gingras 2010; Huang and Chang 2011; Chang and Huang 2012). Typically, two methods have been used for this measurement. The first method uses a citation ratio, which is a method to measure interdisciplinarity based on the percentage of papers citing specific terms. (Lariviere and Gingras 2010) analysed the relationships between the interdisciplinarity of disciplines and research outcomes using research papers as the unit of analysis. They measured interdisciplinarity based on the percentage of references that each paper included that referred to papers in categories (i.e. topical fields) other than its own. The second method 
measures interdisciplinarity by using indices, such as the Brillouin index or Betweeness centrality. (Steele and Stier 2000) used the Brillouin index to measure the interdisciplinarity of the environmental science field. Based on their analysis of the relationships between the interdisciplinarity and use rate of the 750 papers published in the journal Forest Science between 1984 and 1994, they pointed out the limitations of the COC (citation outside category) method of conventional interdisciplinary research and argued that a diversity index should be applied to improve the method. They particularly emphasized that the Brillouin index among diversity indices had proven to be extremely flexible thus far when applied to diverse samples from many fields.

Research has also been conducted in specific domains to measure interdisciplinarity in various methods. Among them, interdisciplinary research was prolific in Nano science because it is not a new science, but rather an agglomeration of currently conducted advanced research, such as physics, chemistry, biology, computer engineering, and medical science (Braun and Schubert 2003) analysed research papers that included the term 'nano' in their titles published between 1986 and 1995, and (Schummer 2004) examined collaboration patterns among researchers through co-authorship. Wang, Notten and Surpatean (2013) analysed interdisciplinary relationships among the five sub-disciplines of nano science by drawing on the co-word method based on keyword mining.

Among the research conducted to measure interdisciplinarity using indices in the field of library and information science (LIS), (Tang 2004) used the Brillouin index for the first time to measure the interdisciplinarity of LIS, and (Huang and Chang 2011) also used the Brillouin index. (Leydesdorff 2007) used Betweeness centrality in addition to the Brillouin index in order to measure the interdisciplinarity of academic journals. He compared the results of interdisciplinarity measurements in each centrality criterion and revealed that Betweeness centrality is more appropriate than degree centrality or closeness centrality as an interdisciplinarity index.

\section{Author Keywords}

Terms that can represent a research paper include not only author keywords, but also terms extracted from the titles, abstracts, and contents. Studies using such extracted terms, and relationships among disciplines have also been examined through network analysis (Marschavova 2005; Cho 2011). However, there are fundamental differences between the keywords used in those studies and author keywords, which are the target of analysis in this research. Because those studies extracted frequently used terms from research papers in a mechanical way, the intentional process of their being 'personally selected and given to papers by their authors' cannot be included at all. Of course, the fact that some terms frequently appeared in research papers indirectly reflects that they are important terms that can represent the paper topics; however, they are different from author keywords selected by researchers and given to the papers personally. In other words, the reason why this research focused on author keywords was that they reflect the researchers' intentions, as they purposefully choose author keywords that are the most 'important' terms to represent their papers.

The importance of author keywords has been emphasized in various studies on them (Taghva et al. 2004; Gross and Taylor 2005; Gil-Leiva and Alonso-Arroyo 2007; Hurt 2010; Lu and Kipp 2014;). (Lu and Kipp 2014) examined search efficiency through an analysis of author keywords and tags in medical journals. (Gil-Leiva and Alonso-Arroyo 2007) compared the author keywords and descriptors of research papers within the INSPEC, CAB, ISTA, and LISA databases. They revealed that almost 46 percent of author keywords appeared in 
descriptors. This means that half the author keywords given to papers appear either as they are or in the same form as the descriptors through normalization, and it also suggests the possibility that author keywords can be used as a controlled vocabulary. There is also research on author keywords used by authors or editors (Gbur and Trumbo 1995; Hartley and Kostoff 2003) or on their characteristics as meta-tags (Alimohammadi 2003; Craven 2004). Prior research conducted in relation to author keywords commonly emphasized their importance in research papers and addressed their usability. This implies that specific author keywords selected by researchers, as they believed that the keywords were important, not only represent the topics of the papers but can also be analysed and utilised in various ways. In particular, the analysis of the interdisciplinarity of author keywords in this research can provide a basis for use of author keywords in a broad range.

\section{MATERIALS AND METHOD}

The data used in this research are the revised data of the Korea Citation Index $(\mathrm{KCl})$. They refer to 59,120 author keywords, which exclude keywords and author keywords with a single appearance from the 533,862 found in the total of 264,338 research papers published on the $\mathrm{KCl}$ of the National Research Foundation of Korea from 2007 to 2011 (80,546 in humanities; 114,706 in social sciences; and 69,086 in art \& physical education).

To examine the interdisciplinary characteristics of author keywords, it is necessary to understand the disciplines with which author keywords are associated. However, since the disciplines cannot be directly known, a way of indirectly judging them was used. In other words, structure-wise, author keywords belong to a paper and the paper belongs to a journal. All pf the journals have topic classifications which represent disciplines. Through this structure, the disciplines of author keywords are determined, and the interdisciplinarity of author keywords was measured. Based on the discipline classification table of the National Research Foundation of Korea, the $\mathrm{KCl}$ lists 23, 22, and 12 sub-disciplines within the humanities, social sciences, and arts \& physical education fields, respectively, as shown in Table 1.

Table 1: Data Summary for this Study

\begin{tabular}{|c|c|c|c|c|c|}
\hline Broad field & Discipline & $\begin{array}{l}\text { No. of } \\
\text { articles }\end{array}$ & $\begin{array}{l}\text { No of } \\
\text { journals }\end{array}$ & $\begin{array}{l}\text { No of article } \\
\text { keywords }\end{array}$ & $\begin{array}{l}\text { No of analysis } \\
\text { keywords }\end{array}$ \\
\hline \multirow{16}{*}{ Humanities } & Humanities & 3,206 & 19 & 11,879 & 1789 \\
\hline & Lexicography & 38 & 1 & 177 & 11 \\
\hline & History & 11,297 & 96 & 38,390 & 3525 \\
\hline & Philosophy & 5,991 & 44 & 16,743 & 3635 \\
\hline & Religion & 1,403 & 11 & 5,664 & 849 \\
\hline & Theology & 3,943 & 27 & 10,386 & 2335 \\
\hline & Catholic Theology & 344 & 6 & 1,640 & 286 \\
\hline & Confucianism & 610 & 4 & 1,771 & 692 \\
\hline & Buddhism & 1,067 & 9 & 4,086 & 711 \\
\hline & Linguistics & 3,886 & 17 & 6,867 & 1224 \\
\hline & Literature & 1,810 & 7 & 247 & 11 \\
\hline & Korean Literature & 14,962 & 86 & 44,435 & 8314 \\
\hline & Chinese Literature & 5,790 & 18 & 3,838 & 474 \\
\hline & Japanese Literature & 5,677 & 16 & 7,219 & 973 \\
\hline & Asian Literature & 248 & 3 & 1,201 & 93 \\
\hline & English Literature & 6,723 & 33 & 10,781 & 2147 \\
\hline
\end{tabular}


Characteristics of Interdisciplinary Research in Author Keywords Appearing in Korean Journals

\begin{tabular}{|c|c|c|c|c|c|}
\hline & French Literature & 2,109 & 8 & 8,324 & 1474 \\
\hline & German Literature & 1,960 & 11 & 6,223 & 1196 \\
\hline & Spanish Literature & 107 & 2 & 310 & 11 \\
\hline & Russian Literature & 990 & 5 & 3,834 & 705 \\
\hline & Classic Literature & 138 & 1 & 660 & 87 \\
\hline & Translation & 568 & 3 & 906 & 120 \\
\hline & Other Humanities & 7,679 & 60 & 26,158 & 4474 \\
\hline \multirow{22}{*}{$\begin{array}{c}\text { Social } \\
\text { sciences }\end{array}$} & Social Science & 4,372 & 29 & 15,959 & 6299 \\
\hline & General Social Science & 5,548 & 36 & 16,961 & 6415 \\
\hline & Political Science & 4,670 & 29 & 12,712 & 4221 \\
\hline & Economics & 6,432 & 41 & 14,275 & 2780 \\
\hline & Agricultural Economics & 1,032 & 4 & 533 & 73 \\
\hline & Business Administration & 11,666 & 62 & 19,150 & 6702 \\
\hline & Accounting & $1,1,547$ & 10 & 3,372 & 797 \\
\hline & Business, Finance & 3,395 & 29 & 5,300 & 2538 \\
\hline & Social Science & $1,1,919$ & 29 & 7,221 & 2346 \\
\hline & Social Welfare & 4,120 & 25 & 9,604 & 2136 \\
\hline & Regional Studies & 3,549 & 29 & 10,219 & 1611 \\
\hline & Education & 20,836 & 124 & 41,060 & 9428 \\
\hline & Law & 18,140 & 101 & 53,522 & 13666 \\
\hline & Public Administration & 5,347 & 29 & 13,085 & 5455 \\
\hline & Policy Science & 2,534 & 13 & 7,078 & 1082 \\
\hline & Geography & 2,243 & 12 & 7,721 & 1304 \\
\hline & Regional Development & 2,132 & 11 & 5,780 & 910 \\
\hline & Tourism Science & 4,791 & 12 & 6,770 & 1681 \\
\hline & Mass Communication & 3,589 & 22 & 10,300 & 2252 \\
\hline & Military Science & 228 & 2 & 365 & 11 \\
\hline & Psychology & 3,086 & 18 & 7,442 & 1744 \\
\hline & Other Social Science & 3,530 & 25 & 7,192 & 1277 \\
\hline \multirow{12}{*}{$\begin{array}{c}\text { Arts \& } \\
\text { Physical } \\
\text { Education } \\
\text { (P/E) }\end{array}$} & Art/PE & 4,372 & 15 & 1,923 & 272 \\
\hline & General Arts & 5,548 & 11 & 5,396 & 887 \\
\hline & Musicology & 4,670 & 26 & 4,557 & 738 \\
\hline & Arts & 6,432 & 32 & 7,740 & 1141 \\
\hline & Design & 1,032 & 28 & 8,884 & 1787 \\
\hline & Fashion Design & 11,666 & 4 & 2,113 & 337 \\
\hline & Fine Arts & 1,547 & 32 & 1,259 & 219 \\
\hline & Film Studies & 3,395 & 9 & 1,297 & 143 \\
\hline & Theatre Studies & 1,919 & 3 & 662 & 71 \\
\hline & Physical Education & 4,120 & 67 & 7,315 & 972 \\
\hline & Dance Studies & 3,549 & 9 & 2,052 & 327 \\
\hline & General Art/PE & 20,836 & 25 & 3,104 & 439 \\
\hline
\end{tabular}

The Brillouin index was selected as a method to measure the interdisciplinarity of author keywords. It has been used to assess the interdisciplinarity of academic journals (Huang and Chang, 2011; Chang and Huang 2012). Initially, it was used as one of the methods to measure alpha diversity indices in ecology. These indices are based on 'diversity', the concept of information theory presented by Shannon and Weaver (Shannon and Weaver 1949). This theory draws on the premise that if diversity is high, uncertainty is high; if diversity is low, uncertainty is also low. Besides the Brillouin Index, the Shannon Weaver Index or the Simson Index can also measure alpha diversity indices. Depending on the target scopes and 
purposes, the Evenness index, Dominance, and Richness Index are also measured. To measure multiple indices, substituted values (the target of analysis) should be used only after modifications. A variable concerning the complexity of term topics refers to the number of terms used in a relevant field in relation to the number of terms within all fields. The model is as follows:

Interdisciplinarity degree (Brillouin index:HB)

$$
H B=\frac{1}{N} \ln \frac{N !}{n_{1} ! n_{2} ! n_{3} ! \ldots}=\frac{\ln N !-\sum \ln n_{i}}{N}
$$

where $\quad N=$ The number of terms that belong to all fields

$n_{i}=$ The number of terms that belong to $i$ field

In this research, the measurement was taken in two cases: one was when terms whose Brillouin index value was 'zero' were included, and the other was when such terms were excluded. This was based on the premise of the fact that the Brillouin index value of a specific term being zero means that it appears only in one discipline and thus indicates that it has no interdisciplinarity or is not interdisciplinary. In other words, if terms whose value is zero are included, the average interdisciplinarity degree of a relevant discipline can be assessed. In contrast, if terms whose value is zero are not included, the average interdisciplinarity degree of interdisciplinary author keywords in a relevant field can be assessed.

\section{FINDINGS}

\section{The Interdisciplinarity Degree of each Term}

The data used in this research are the revised data of the Korea Citation Index $(\mathrm{KCl})$, which was collected to build STNET (Structural Terminology net). They refer to 59,120 author keywords, which exclude keywords and author keywords with a single appearance from the 533,862 found in the total of 264,338 research papers published on the $\mathrm{KCl}$ of the National Research Foundation of Korea from 2007 to 2011 (80,546 in humanities; 114,706 in social sciences; and 69,086 in arts \& physical education).

\section{Terms in order of Interdisciplinarity Degree}

Among the top 25 terms in all disciplines, the term with the highest index value was 'Japan' (3.16345), followed by 'image' (3.08891), 'globalization' (3.05531), and 'culture' (2.98351). Next, the fields of keywords were examined. There were 10 in the humanities and 15 in the social sciences, and there was no keyword relevant to arts \& physical education. Of course, this does not mean that keywords did not appear at all in the field of arts \& physical education. Their appearance frequency in this field was relatively low in comparison to the humanities and social sciences. The minimum of the index values is zero, which means that author keywords are used in only one field and indicates that there is no topic complexity. It was revealed that 'body composition' (0.00849) was the term with the lowest value, excepting those terms with an index value of zero. Table 2 presents the findings. 
Table 2: Keywords with the Top 25 Interdisciplinarity Degree

\begin{tabular}{|c|c|c|c|c|c|c|c|c|c|}
\hline Rank & Term & Degree & $\begin{array}{l}\mathrm{A} / \mathrm{B} \\
/ \mathrm{G}^{*}\end{array}$ & $\begin{array}{r}\text { Count in } \\
\text { Humanities }\end{array}$ & $\begin{array}{r}\% \\
\text { Humanities }\end{array}$ & $\begin{array}{r}\text { Count in } \\
\text { Social } \\
\text { Sciences }\end{array}$ & $\begin{array}{r}\% \\
\text { Social } \\
\text { Science }\end{array}$ & $\begin{array}{l}\text { Count in } \\
\text { Arts \& PE }\end{array}$ & $\begin{array}{r}\% \text { Arts } \\
\& \mathrm{PE}\end{array}$ \\
\hline 1 & Japan & 3.16345 & B & 164 & $35.4 \%$ & 282 & $60.9 \%$ & 17 & $3.7 \%$ \\
\hline 2 & Image & 3.08891 & A & 212 & $45.1 \%$ & 135 & $28.7 \%$ & 123 & $26.2 \%$ \\
\hline 3 & Globalization & 3.05531 & B & 146 & $29.1 \%$ & 326 & $64.9 \%$ & 30 & $6.0 \%$ \\
\hline 4 & Culture & 2.98351 & A & 371 & $61.3 \%$ & 167 & $27.6 \%$ & 67 & $11.1 \%$ \\
\hline 5 & Postmodernism & 2.98041 & A & 100 & $40.8 \%$ & 75 & $30.6 \%$ & 70 & $28.6 \%$ \\
\hline 6 & Writing & 2.97337 & A & 219 & $94.4 \%$ & 11 & $4.7 \%$ & 2 & $0.9 \%$ \\
\hline 7 & Multiculturalism & 2.85490 & B & 167 & $43.7 \%$ & 204 & $53.4 \%$ & 11 & $2.9 \%$ \\
\hline 8 & Conflict & 2.84810 & B & 67 & $32.5 \%$ & 129 & $62.6 \%$ & 10 & $4.9 \%$ \\
\hline 9 & Network & 2.82240 & B & 38 & $16.0 \%$ & 187 & $78.6 \%$ & 13 & $5.5 \%$ \\
\hline 10 & China & 2.78834 & B & 298 & $31.4 \%$ & 626 & $65.9 \%$ & 26 & $2.7 \%$ \\
\hline 11 & Korean Wave & 2.78247 & B & 64 & $37.2 \%$ & 101 & $58.7 \%$ & 7 & $4.1 \%$ \\
\hline 12 & Education & 2.77665 & A & 197 & $55.5 \%$ & 141 & $39.7 \%$ & 17 & $4.8 \%$ \\
\hline 13 & Media & 2.74508 & A & 74 & $47.1 \%$ & 55 & $35.0 \%$ & 28 & $17.8 \%$ \\
\hline 14 & Symbol & 2.70807 & A & 132 & $64.4 \%$ & 22 & $10.7 \%$ & 51 & $24.9 \%$ \\
\hline 15 & Power & 2.70251 & A & 99 & $61.9 \%$ & 52 & $32.5 \%$ & 9 & $5.6 \%$ \\
\hline 16 & Publicity & 2.69703 & B & 51 & $29.1 \%$ & 96 & $54.9 \%$ & 28 & $16.0 \%$ \\
\hline 17 & Sustainability & 2.69142 & B & 18 & $15.0 \%$ & 86 & $71.7 \%$ & 16 & $13.3 \%$ \\
\hline 18 & Orientalism & 2.68362 & A & 118 & $76.1 \%$ & 23 & $14.8 \%$ & 14 & $9.0 \%$ \\
\hline 19 & $\begin{array}{l}\text { Multicultural } \\
\text { Society }\end{array}$ & 2.67976 & B & 97 & $30.7 \%$ & 214 & $67.7 \%$ & 5 & $1.6 \%$ \\
\hline 20 & America & 2.67408 & A & 63 & $27.4 \%$ & 163 & $70.9 \%$ & 4 & $1.7 \%$ \\
\hline 21 & Value & 2.67197 & B & 43 & $29.5 \%$ & 81 & $55.5 \%$ & 22 & $15.1 \%$ \\
\hline 22 & Religion & 2.66749 & B & 149 & $68.7 \%$ & 68 & $31.3 \%$ & 0 & $0.0 \%$ \\
\hline 23 & Change & 2.65037 & B & 89 & $71.2 \%$ & 30 & $24.0 \%$ & 6 & $4.8 \%$ \\
\hline 24 & Diversity & 2.64672 & B & 55 & $29.9 \%$ & 119 & $64.7 \%$ & 10 & $5.4 \%$ \\
\hline 25 & Environment & 2.64550 & B & 34 & $26.6 \%$ & 80 & $62.5 \%$ & 14 & $10.9 \%$ \\
\hline
\end{tabular}

\begin{tabular}{|c|c|c|c|c|c|c|c|c|c|}
\hline 21770 & $\begin{array}{l}\text { Practical Arts } \\
\text { Education }\end{array}$ & 0.06136 & $A$ & 1 & $1.4 \%$ & 68 & $98.6 \%$ & 0 & $0.0 \%$ \\
\hline 21771 & Taekwondo & 0.04154 & G & 2 & $0.5 \%$ & 10 & $2.3 \%$ & 421 & $97.2 \%$ \\
\hline 21772 & Body Composition & 0.00849 & G & 0 & $0.0 \%$ & 0 & $0.0 \%$ & 385 & $100.0 \%$ \\
\hline
\end{tabular}

\begin{tabular}{llllllllll}
\hline \hline 59120 & Hippocrates & 0 & B & 2 & $100.0 \%$ & 0 & $0.0 \%$ & 0 & $0.0 \%$ \\
\hline
\end{tabular}

* A: Humanities, B: Social Science, G: Art \& Physical

\section{Terms in order of the Interdisciplinarity Degree in each Field}

The terms in order of interdisciplinarity index value in the fields of the humanities, social sciences, and art/physical education are shown in Table 3. The terms with the highest index value were 'Image' (3.08891) in humanities and 'Japan' (3.16345) in social sciences. It was 'Virtual Reality' (2.38394) in art/physical education. This value, though the highest in the field, was significantly lower than the values in the humanities and social sciences. 
Kwon,S.

Table 3: Top 25 keywords in the Humanities, Social Sciences, and Arts \& Physical Education

\begin{tabular}{|c|c|c|c|c|c|c|c|c|}
\hline \multirow{2}{*}{ Rank } & \multicolumn{2}{|l|}{ Humanities } & \multirow{2}{*}{ Rank } & \multicolumn{2}{|l|}{ Social Science } & \multirow{2}{*}{ Rank } & \multicolumn{2}{|c|}{ Art \& Physical Education } \\
\hline & Term & Degree & & Term & Degree & & Term & Degree \\
\hline 1 & Image & 3.08891 & 1 & Japan & 3.16345 & 1 & Virtual Reality & 2.38394 \\
\hline 2 & Culture & 2.98351 & 2 & Globalization & 3.05531 & 2 & Preference & 2.26819 \\
\hline 3 & Post modernism & 2.98041 & 3 & Multiculturalism & 2.85490 & 3 & Communication & 2.19901 \\
\hline 4 & Writing & 2.97337 & 4 & Conflict & 2.84810 & 4 & Symbolism & 2.18406 \\
\hline 5 & Education & 2.77665 & 5 & Network & 2.82240 & 5 & Cultural Product & 2.09913 \\
\hline 6 & Media & 2.74508 & 6 & China & 2.78834 & 6 & Animation & 2.08437 \\
\hline 7 & Symbol & 2.70807 & 7 & Korean Wave & 2.78247 & 7 & Lifestyle & 2.07568 \\
\hline 8 & Power & 2.70251 & 8 & Publicity & 2.69703 & 8 & Brand & 2.03623 \\
\hline 9 & Orientalism & 2.68362 & 9 & Sustainability & 2.69142 & 9 & Digital & 2.02609 \\
\hline 10 & Religion & 2.66749 & 10 & $\begin{array}{l}\text { Multicultural } \\
\text { Society }\end{array}$ & 2.67976 & 10 & Display & 1.92795 \\
\hline 11 & Change & 2.65037 & 11 & America & 2.67408 & 11 & Participation & 1.91851 \\
\hline 12 & Reappearance & 2.64445 & 12 & Value & 2.67197 & 12 & Design & 1.88678 \\
\hline 13 & Communication & 2.63657 & 13 & Diversity & 2.64672 & 13 & New Media & 1.88517 \\
\hline 14 & Politic & 2.60770 & 14 & Environment & 2.64550 & 14 & Flexibility & 1.88016 \\
\hline 15 & Communication & 2.59279 & 15 & Neoliberalism & 2.64251 & 15 & $\begin{array}{l}\text { Purchase } \\
\text { behaviour }\end{array}$ & 1.87140 \\
\hline 16 & Cultural Industries & 2.58984 & 16 & Multi Culture & 2.62955 & 16 & Identity & 1.83910 \\
\hline 17 & History & 2.58941 & 17 & Comparative Study & 2.61390 & 17 & Character & 1.83685 \\
\hline 18 & Art & 2.58181 & 18 & Fusion & 2.59919 & 18 & Type & 1.83323 \\
\hline 19 & Movie & 2.56885 & 19 & Policy & 2.59725 & 19 & Arts Education & 1.82657 \\
\hline 20 & Aesthetics & 2.56334 & 20 & Contents & 2.58497 & 20 & Characteristic & 1.81496 \\
\hline 21 & Memory & 2.55682 & 21 & Individualism & 2.57573 & 21 & $\begin{array}{l}\text { Aesthetic } \\
\text { experience }\end{array}$ & 1.78583 \\
\hline 22 & Recognition & 2.55066 & 22 & Satisfaction & 2.57028 & 22 & Deconstruction & 1.76501 \\
\hline 23 & Area & 2.55049 & 23 & Case Study & 2.56375 & 23 & Museum & 1.71753 \\
\hline 24 & Nationalism & 2.54098 & 24 & Cooperation & 2.55322 & 24 & Digital Media & 1.70420 \\
\hline 25 & Methodology & 2.54095 & 25 & Advertising & 2.55226 & 25 & Arts & 1.70383 \\
\hline \multicolumn{9}{|l|}{. } \\
\hline 6053 & $\begin{array}{l}\text { Christian } \\
\text { counselling }\end{array}$ & 0.11889 & 14231 & Learning Attitude & 0.09057 & 880 & Fitness & 0.07796 \\
\hline 6054 & Yates & 0.10266 & 14232 & Medical care & 0.08600 & 881 & Taekwondo & 0.04155 \\
\hline 6055 & Chinese character & 0.07693 & 14233 & $\begin{array}{l}\text { Practical Arts } \\
\text { Education }\end{array}$ & 0.06136 & 882 & Body Composition & 0.00849 \\
\hline \multicolumn{9}{|l|}{. } \\
\hline \multicolumn{9}{|l|}{$\cdot$} \\
\hline 19398 & Hip-hop & 0 & 35572 & Hippocrates & 0 & 3550 & Histamine & 0 \\
\hline
\end{tabular}

\section{Interdisciplinarity Degree Average in the Humanities}

The interdisciplinarity degree average of each sub-discipline in the humanities is shown in Table 4. Some sub-disciplines share the maximum value, 3.16345, and the keyword associated with this value is 'Japan'. This suggests that the author keyword 'Japan' has often been used in the sub-disciplines of the humanities and that research related to 'Japan' has 
been conducted. In contrast, the minimum values vary, which indicates that there exist terms with a low topic complexity in each sub-discipline.

Next, the average of each sub-discipline was examined in two cases: one was when terms with an interdisciplinarity degree of 'zero' were included, and the other was when such terms were excluded. In the previous case, the sub-discipline with the highest average was Catholic Theology, and the one with the lowest average was Buddhism. In the latter case, they were Catholic Theology and Translation, respectively.

Table 4: Summary of the Interdisciplinarity Degree of each Sub-discipline in the Humanities

\begin{tabular}{|c|c|c|c|c|c|}
\hline Discipline & Count & Min. & Max & $\begin{array}{c}\text { Average } \\
\text { (include 0) }\end{array}$ & $\begin{array}{c}\text { Average } \\
\text { (exclude 0) }\end{array}$ \\
\hline Humanities & 1789 & 0.20189 & 3.16345 & 1.03424 & 1.24178 \\
\hline Lexicography & 11 & 0.39817 & 1.69950 & 0.76474 & 0.93468 \\
\hline History & 3525 & 0.14050 & 3.16345 & 0.65505 & 1.04909 \\
\hline Philosophy & 3635 & 0.13633 & 3.16345 & 0.64995 & 1.12557 \\
\hline Religion & 849 & 0.12776 & 3.16345 & 0.78936 & 1.15149 \\
\hline Theology & 2335 & 0.11889 & 3.08891 & 0.71622 & 1.23788 \\
\hline Catholic Theology & 286 & 0.33513 & 3.05531 & 1.18013 & 1.62268 \\
\hline Confucianism & 692 & 0.06136 & 3.16345 & 1.10636 & 1.20000 \\
\hline Buddhism & 711 & 0.53677 & 3.16345 & 0.48284 & 1.04665 \\
\hline Linguistics & 1224 & 0.13106 & 3.08891 & 0.76121 & 1.05350 \\
\hline Literature & 11 & 0.68024 & 2.64445 & 0.88644 & 1.39298 \\
\hline Korean Literature & 8314 & 0.07693 & 3.16345 & 0.49393 & 0.98172 \\
\hline Chinese Literature & 474 & 0.14021 & 3.08891 & 0.94760 & 1.30192 \\
\hline Japanese Literature & 973 & 0.20625 & 3.16345 & 0.81728 & 1.30792 \\
\hline Asian Literature & 93 & 0.36620 & 3.08891 & 0.87140 & 1.22788 \\
\hline English Literature & 2147 & 0.10266 & 3.16345 & 0.55470 & 1.09061 \\
\hline French Literature & 1474 & 0.20190 & 3.08891 & 0.81493 & 1.36811 \\
\hline German Literature & 1196 & 0.17251 & 2.98041 & 0.84514 & 1.33349 \\
\hline Spanish Literature & 11 & 0.41653 & 3.08891 & 0.73989 & 1.01735 \\
\hline Russian Literature & 705 & 0.24508 & 3.08891 & 0.87073 & 1.35510 \\
\hline Classic Literature & 87 & 0.36430 & 2.65307 & 1.00443 & 1.34439 \\
\hline Translation & 120 & 0.07693 & 2.74508 & 0.57363 & 0.96951 \\
\hline Other Humanities & 4474 & 0.04155 & 3.16345 & 0.83658 & 1.07925 \\
\hline
\end{tabular}

\section{Interdisciplinarity Degree in the Social Sciences}

The interdisciplinarity degree of each sub-discipline in the social sciences is shown in Table 5. Some sub-disciplines share the maximum value, 3.16345, and the keyword associated with this value is 'Japan'. This suggests that the author keyword 'Japan' has often been used in the sub-disciplines of the humanities and that research related to 'Japan' has been conducted. In contrast, the minimum values vary, which indicates that there exist terms with a low topic complexity in each sub-discipline.

Next, the average of each sub-discipline was examined in two cases: one was when terms with a degree of 'zero' were included, and the other was when such terms were excluded. In the previous case, the sub-discipline with the highest average was Catholic Theology, and the one with the lowest average was Buddhism. In the latter case, they were Catholic Theology and Translation, respectively. 
Kwon,S.

Table 5: Summary of the Interdisciplinarity Degree of each Sub-discipline in the Social Sciences

\begin{tabular}{|c|c|c|c|c|c|}
\hline Discipline & Count & Min & Max & $\begin{array}{r}\text { Average } \\
\text { (include 0) }\end{array}$ & $\begin{array}{r}\text { Average } \\
\text { (exclude 0) }\end{array}$ \\
\hline Social Science & 6299 & 0.04155 & 3.16345 & 0.84970 & 0.83998 \\
\hline General Social Science & 6415 & 0.07964 & 3.16345 & 0.90789 & 0.91907 \\
\hline Political Science & 4221 & 0.09222 & 3.16345 & 0.92192 & 0.97775 \\
\hline Economics & 2780 & 0.14050 & 3.16345 & 0.75411 & 1.05349 \\
\hline Agricultural Economics & 73 & 0.25462 & 2.78884 & 0.76324 & 1.09248 \\
\hline Business Administration & 6702 & 0.09507 & 3.16345 & 0.65690 & 0.83897 \\
\hline Accounting & 797 & 0.23418 & 3.08881 & 0.63929 & 0.93130 \\
\hline Business, Finance & 2538 & 0.04155 & 3.16345 & 0.75207 & 0.86369 \\
\hline Social Science & 2346 & 0.15497 & 3.16345 & 1.06024 & 1.17939 \\
\hline Social Welfare & 2136 & 0.07996 & 3.16345 & 0.77429 & 1.07605 \\
\hline Regional Studies & 1611 & 0.16572 & 3.16345 & 0.98441 & 1.26668 \\
\hline Education & 9428 & 0.04155 & 3.16345 & 0.46888 & 0.96278 \\
\hline Law & 13666 & 0.07942 & 3.16345 & 0.29901 & 0.75143 \\
\hline Public Administration & 5455 & 0.10505 & 3.16345 & 0.77573 & 0.88751 \\
\hline Policy Science & 1082 & 0.16944 & 3.16345 & 1.07081 & 1.26211 \\
\hline Geography & 1304 & 0.12776 & 3.16345 & 0.70577 & 1.23866 \\
\hline Regional Development & 910 & 0.20655 & 3.16345 & 0.85864 & 1.16621 \\
\hline Tourism Science & 1681 & 0.12207 & 3.16345 & 0.72187 & 1.10015 \\
\hline Mass Communication & 2252 & 0.12207 & 3.16345 & 0.74615 & 1.16366 \\
\hline Military Science & 11 & 0.34657 & 2.74508 & 1.43268 & 1.43268 \\
\hline Psychology & 1744 & 0.14642 & 3.08891 & 0.73267 & 1.11015 \\
\hline Other Social Science & 1277 & 0.11889 & 3.16345 & 0.98578 & 1.20463 \\
\hline
\end{tabular}

Some sub-disciplines in the social sciences also share the same maximum value, 3.16345, and the author keyword associated with this value is 'Japan'. This indicates that many studies have been conducted on the topic of 'Japan', even in the social sciences.

Next, the average of each sub-discipline was examined in two cases: one was when terms with degree 'zero' were included, and the other was when such terms were excluded. In the previous case, the sub-discipline with the highest average was Military Science, and the one with the lowest average was Law. In the latter case, they were also Military Science and Law, respectively.

\section{Interdisciplinarity Degree Average in Arts \& Physical Education}

The interdisciplinarity degree of each sub-discipline in the arts \& physical education is shown in Table 6. Some sub-disciplines share the maximum value, 3.16345, and the keyword associated with this value is 'Image'. This suggests that the author keyword 'Image' has often been used in the sub-disciplines of the arts \& physical education and that research related to 'Image' has been conducted. In contrast, the minimum values vary, which indicates that there exist terms with a low topic complexity in each sub-discipline.

Next, the average of each sub-discipline was examined in two cases: one was when terms with a degree of 'zero' were included, and the other was when such terms were excluded. In the previous case, the sub-discipline with the highest average was Theatre Studies, and the one with the lowest average was Arts. In the latter case, they Theatre Studies and Musicology, respectively. 
Table 6: Summary of the Interdisciplinarity Index of each Sub-discipline in Arts \& Physical Education.

\begin{tabular}{|c|c|c|c|c|c|}
\hline Discipline & Count & Min & Max & $\begin{array}{l}\text { Average } \\
\text { (include 0) }\end{array}$ & $\begin{array}{l}\text { Average } \\
\text { (exclude 0) }\end{array}$ \\
\hline Art/PE & 272 & 0.04155 & 2.98041 & 0.71943 & 1.15207 \\
\hline General Arts & 887 & 0.11611 & 3.16415 & 1.06178 & 1.30443 \\
\hline Musicology & 738 & 0.22146 & 3.05331 & 0.44796 & 1.15190 \\
\hline Arts & 1141 & 0.14162 & 3.16415 & 0.81290 & 1.25171 \\
\hline Design & 1787 & 0.12207 & 3.16415 & 0.74979 & 1.18573 \\
\hline Fashion Design & 337 & 0.28898 & 3.16415 & 0.64519 & 1.18814 \\
\hline Fine Arts & 219 & 0.31026 & 3.08891 & 0.63913 & 1.21713 \\
\hline Film Studies & 143 & 0.22146 & 3.08891 & 0.97714 & 1.36991 \\
\hline Theatre Studies & 71 & 0.21070 & 3.08891 & 1.13580 & 1.46621 \\
\hline Physical Education & 972 & 0.08849 & 3.08891 & 0.73568 & 1.13504 \\
\hline Dance Studies & 327 & 0.07796 & 3.08891 & 0.80060 & 1.28331 \\
\hline General Art/PE & 439 & 0.00849 & 3.08891 & 0.96008 & 1.35960 \\
\hline
\end{tabular}

\section{The distribution and characteristics of interdisciplinarity degree in each discipline}

\section{a) The distributions of interdisciplinarity degree}

The Interdisciplinarity degree are between 0 and 3.5. The number of author keywords with a value of zero is 37347 out of 59120 (63.17 percent). This means that they appear in one discipline; they are terms without a term-topic complexity, that is, with no interdisciplinarity. The number of author keywords with a relatively low value, between 0.01 and 0.49 , was 10493. In sum, the number of author keywords associated with values between 0 and 0.49 is 47840 , and they constitute 80.92 percent of the total. The number of author keywords with a high index value is considerably low. This is because relatively few terms appear across many fields.

An examination of the number of disciplines in which terms in each value range appear revealed that the average in the lower range, between 0.01 and 0.49 , is two; the higher index values increases as the number of disciplines does. The average number of disciplines in which the author keyword is associated with the highest range (between 3.0 and 3.49) appeared was as many as 31.25 (Table 7).

\section{b) The Distributions of Interdisciplinarity Degree and Differences among the Disciplines}

The distributions of the interdisciplinarity degree in the humanities, social sciences, and arts \& physical education are shown in Table 8 . In this study, they were examined in two cases: one was when terms with the interdisciplinarity degree of 'zero' were included, and the other was when such terms were excluded. In the former case, the average interdisciplinarity degree of a discipline could be assessed; in the latter case, that of the author keywords with interdisciplinarity could be assessed.

When the averages of the interdisciplinarity degree in each discipline were compared, social sciences was found to be highest $(0.26260)$, followed by the humanities $(0.24297)$ and arts \& physical education (0.16111). However, when terms with the interdisciplinarity degree of zero were excluded, the average was highest in the humanities $(0.77838)$, followed by social sciences (0.65629) and arts \& physical education (0.64844). This revealed that inclusion or 
exclusion of terms with the interdisciplinarity degree of zero makes a difference. Especially, it is notable that the difference between the interdisciplinarity degree of the social sciences and art/physical education is trivial when terms with the interdisciplinarity degree of zero are excluded. The comparison of the number of disciplines in which author keywords were associated with each index range appeared indicates that, in all of the ranges, as the index value increases, the number of disciplines in which author keywords appear also increases; it is the highest in the social sciences, followed by the humanities and art/physical education (Table 8).

Table 7: The Number of Author Keywords and the Average Number of Disciplines in which They Appear in each Degree Range

\begin{tabular}{c||c||c|c}
\hline \hline Degree range & No. of keywords & $\%$ & $\begin{array}{c}\text { Average no. of } \\
\text { disciplines }\end{array}$ \\
\hline \hline 0 & 37347 & 63.17 & 1 \\
$0.01 \sim 0.49$ & 10493 & 17.75 & 2.06 \\
$0.5 \sim 0.99$ & 7153 & 12.10 & 3.35 \\
$0.99 \sim 1.49$ & 2762 & 4.67 & 6.06 \\
$1.50 \sim 1.99$ & 975 & 1.65 & 10.46 \\
$2.0 \sim 2.49$ & 326 & 0.55 & 17.38 \\
$2.50 \sim 2.99$ & 58 & 0.10 & 26.18 \\
$3.0 \sim 3.49$ & 6 & 0.01 & 31.25 \\
\hline \hline $0 \sim 3.49$ & 59,120 & 100 & 13.82 \\
\hline \hline
\end{tabular}

Table 8: Differences among the Disciplines in each Interdisciplinarity Degree Range

\begin{tabular}{|c|c|c|c|c|c|c|}
\hline \multirow[b]{2}{*}{ Range } & \multicolumn{2}{|c|}{ Humanities } & \multicolumn{2}{|c|}{ Social Science } & \multicolumn{2}{|c|}{ Art \& Physical Education } \\
\hline & $\begin{array}{r}\text { No. of } \\
\text { keywords }\end{array}$ & $\begin{array}{r}\text { Average no. of } \\
\text { disciplines }\end{array}$ & $\begin{array}{r}\text { No. of } \\
\text { keywords }\end{array}$ & $\begin{array}{l}\text { Average no. } \\
\text { of disciplines }\end{array}$ & $\begin{array}{r}\text { No. of } \\
\text { keywords }\end{array}$ & $\begin{array}{l}\text { Average no. } \\
\text { of disciplines }\end{array}$ \\
\hline 0 & 13343 & 1.00 & 21338 & 1.00 & 2668 & 1 \\
\hline $0.01 \sim 0.49$ & 2553 & 1.61 & 7103 & 2.02 & 454 & 1.46 \\
\hline $0.5 \sim 0.99$ & 1942 & 2.47 & 4742 & 3.17 & 298 & 2.00 \\
\hline $0.99 \sim 1.49$ & 1003 & 4.10 & 1634 & 5.34 & 88 & 2.90 \\
\hline $1.50 \sim 1.99$ & 389 & 6.47 & 547 & 8.36 & 33 & 3.87 \\
\hline $2.0 \sim 2.49$ & 139 & 9.09 & 176 & 12.17 & 9 & 5.11 \\
\hline $2.50 \sim 2.99$ & 28 & 12.14 & 29 & 14.72 & 0 & 0 \\
\hline $3.0 \sim 3.49$ & 1 & 15.00 & 2 & 17.00 & 0 & 0 \\
\hline $0 \sim 3.49$ & 19,397 & 4.61 & 35,571 & 7.97 & 0 & 0 \\
\hline $\begin{array}{l}\text { Avg degree } \\
\text { (include 0) }\end{array}$ & & 0.24297 & & 0.26260 & & 0.16111 \\
\hline $\begin{array}{l}\text { Avg degree } \\
\text { (exclude 0) }\end{array}$ & & 0.77838 & & 0.65629 & & 0.64844 \\
\hline
\end{tabular}




\section{DISCUSSION}

The following analysis points have been made based on the research results. First, among the top 25 keywords, 10 were from the humanities and 15 were from the social sciences; none of them was from arts \& physical education. Of course, this does not mean that these keywords did not appear in art/physical education at all; rather, the frequency in this discipline was relatively low in comparison to the humanities and social sciences (Table 2). Second, the examination of the interdisciplinary degree each sub-discipline in the humanities, social sciences, and arts \& physical education fields revealed the following results.

In the examination of the interdisciplinary degree of each sub-discipline in the humanities (Table 4), 'Buddhism' showed the greatest average difference between when terms with an interdisciplinarity degree of zero were included and when such terms were excluded. This is because there are a significant number of terms (with a value of zero) pertinent to 'Buddhism' due to the characteristics of the sub-discipline and because these terms rarely appear in other fields. In contrast, there was not a very large average difference in the case of 'Confucianism'. This is because terms pertinent to 'Confucianism', in fact, frequently appear in other areas. It should be noted, however, that this could be unique to South Korea. In South Korea, while 'Confucianism' has been researched as a single discipline, related concepts or terms have also been used as the conceptual and philosophical basis of the humanities and social sciences.

In the examination of the interdisciplinary degree of each sub-discipline in the social sciences, 'Geography' had the largest average difference, which well reflects the characteristics of this field's terms. The sub-discipline that deserves attention in the social science is 'Law' because its average of is low in both cases where terms with the interdisciplinarity degree of zero were included and those where they were excluded. This is because overall terms used in this field are pertinent only to the field itself, i.e. holding term-specificity, rather than being interdisciplinary.

In the examination of the interdisciplinary degree of each sub-discipline in arts \& physical education, 'Musicology' had the greatest average difference, which is even larger than 'Buddhism' in the humanities and 'Geography' in the social sciences. This is because terms used in 'Musicology' are distinct from terms used in other fields, and many of them are rarely used in other fields.

Third, the distributions of the interdisciplinarity degree were examined. Terms with the interdisciplinarity degree of zero constitute 63.17 percent of all of the terms. These author keywords can be regarded as subject oriented terms that have field specificity and appear only in relevant fields. Additionally, the fact that 80 percent of all of the terms fell between 0 and 0.499 indicates that the majority of author keywords are field specific and not interdisciplinary (Table 7).

Fourth, differences among the disciplines in each degree range were examined. The author keywords of art/physical education have less interdisciplinarity than those of the humanities or social sciences (Table 8 ). When the order of interdisciplinarity degree was examined, the top 25 author keywords were associated with the humanities or social sciences (Table 2). When the top 100 author keywords were examined, the keywords from the top to the penultimate rank were associated with the humanities or social sciences; only the last one, 'virtual reality' (2.38394), belongs to arts \& physical education. Even in terms of the 
distributions of index values, the number of author keywords associated with the high index value range was lower in arts \& physical education than in the humanities or social sciences. This suggests that the author keywords of arts \& physical education have higher field specificity and lower interdisciplinarity than those of the humanities or social sciences. Taken together, in the case that an author keyword's interdisciplinarity is high, its field specificity, which means it appears only in a specific field, is low because it appears in many fields. In contrast, in the case that an author keyword's interdisciplinarity is low, it appears only in specific fields and thus is considered to have high field specificity.

\section{CONCLUSION}

This research is significant in that it examined author keywords commonly used in many disciplines from the aspect of interdisciplinarity. It, however, has several limitations. First, there was no detailed stemming process for the author keywords. Since author keywords are provided by researchers, they are characterised as an uncontrolled vocabulary; multiple terms can mean one thing, and both singular and plural forms can be used in terms of formality. For an accurate analysis, there should be a stemming process that draws on the unity of such various factors. However, the multiplicity of author keywords also means a researcher's intentional intervention. Thus, by using author keywords without modifications, we tried to underline the significance of examining their interdisciplinary characteristics based on the actual researcher's behaviour. Second, data were not equally distributed in each discipline. Some disciplines had more journals and consequently more author keywords than others; in some cases, there was only one journal and a very small number of keywords. This limitation made it challenging to generalise interdisciplinarity among disciplines based on a thorough comparison.

In conclusion, it was revealed that the author keywords of academic journals are not generally interdisciplinary. Only a few author keywords with a high interdisciplinarity degree are assumed to be 'frequently researched' topics. An additional aspect that can be drawn from the analyses is that the question, 'What terms do researchers select to provide as author keywords', was answered. In other words, it can be assumed that most researchers select terms that represent particular fields when they provide author keywords and do not use general terms that are frequently used. However, among the few author keywords (1365, 2.31 percent) that appear in more than 10 disciplines, some had a macro concept and generality that rendered it impossible to identify the disciplines in which they are used; such author keywords include 'history', 'culture', 'education', and 'school'. Why did researchers select these terms as author keywords? On the one hand, these author keywords can be regarded as 'frequently researched topics'; on the other, it is questionable why researchers provide such general terms in a limited space where generally only five author keywords can be entered. Addressing such behaviour by researchers in selecting author keywords will be a meaningful future research topic. Additionally, when a network analysis is applied, it is expected that relationships and interdisciplinary meanings focused on terms could be examined in a field network.

\section{ACKNOWLEDGEMENTS}

This work was supported by 2017 Hannam University Research Fund. 


\section{REFERENCES}

Alimohammadi, D. 2003. Meta-tag: A means to control the process of web indexing. Online Information Review, Vol. 27, no. 4: 238-42.

Braun, T. and Schubert, A. 2003. A quantitative view on the coming of age of interdisciplinarity in the sciences 1980-1999. Scientometrics, Vol. 58, no. 1: 183-189.

Chang, Y.W. and Huang, M.H. 2012. A study of the evolution of interdisciplinarity in library and information science: Using three bibliometric methods. Journal of the American Society for Information Science and Technology, Vol. 63, no. 1: 22-33.

Cho, J. 2011. A study for research area of library and information science by network text analysis. Journal of the Korean Society for Information Management, Vol. 28 No. 4: 6583.

Chung, Y.K. 2012. A study of interdisciplinarity in Journal of Korean Society of Archives and Records Management. Journal of Korean Society of Archives and Records Management, Vol. 12, No. 2: 7-27.

Craven, T.C. 2004. Variations in use of meta tag keywords by web pages in different languages. Journal of Information Science, Vol. 30, no. 3: 268-79.

Gbur Jr, E.E. and Trumbo, B.E. 1995. Key words and phrases-the key to scholarly visibility and efficiency in an information explosion. The American Statistician, Vol. 49, no 1: 2933.

Gil-Leiva, I. and Alonso-Arroyo, A. 2007. Keywords given by authors of scientific articles in database descriptors. Journal of the American Society for Information Science and Technology, Vol. 58, no. 8: 1175-1187.

Gross, T. and Taylor, A.G. 2005. What have we got to lose? The effect of controlled vocabulary on keyword searching results. College \& Research Libraries, Vol. 66, no. 3: 212-30.

Haisheng, S. 2012. Author keyword co-occurrence network analysis and empirical research. Journal of Intelligence, Vol. 9: 014.

Hartley, J. and Kostoff, R.N. 2003. How useful are 'key words' in scientific journals? Journal of Information Science, Vol. 29, no. 5: 433-38.

Herring, S.D. 1999. The value of interdisciplinarity: A study based on the design of internet search engines. Journal of the American Society for Information Science, Vol. 50, no 4: 358-65.

Huang, M.H. and Chang, Y.W. 2011. A study of interdisciplinarity in information science: Using direct citation and co-authorship analysis. Journal of Information Science. Vol. 37, no 4: 369-78.

Hurt, C.D. 2010. Automatically generated keywords: A comparison to author-generated keywords in the sciences. Journal of Information and Organizational Sciences, Vol. 34, no 1: 81-88.

Kwon, S.Y. 2014. A study on the factors influencing semantic relation in building a structured glossary. Journal of the Korean Society for Library and Information Science, Vol. 48, no 2: 353-78.

Larivière, V. and Gingras, Y. 2010. On the relationship between interdisciplinarity and scientific impact. Journal of the American Society for Information Science and Technology, Vol. 61, no 1: 126-31.

Lewison, G. and Cunningham, P. 1991. Bibliometric studies for the evaluation of transnational research. Scientometrics, Vol. 21, no 2: 223-44.

Leydesdorff, L. 2007. Betweenness centrality as an indicator of the interdisciplinarity of scientific journals. Journal of the American Society for Information Science and Technology, Vol. 58, no 9: 1303-19. 
Liu, Z. and Zhang, Z. 2010. Author keyword coupling analysis: An empirical research. Journal of the China Society for Scientific and Technical Information, Vol. 29, no 2: 268-75.

Lu, K. and Kipp, M.E. 2014. Understanding the retrieval effectiveness of collaborative tags and author keywords in different retrieval environments: An experimental study on medical collections. Journal of the Association for Information Science and Technology, Vol. 65, no 3: 483-500.

Marshakova-Shaikevich, I. 2005. Bibliometric maps of field of science. Information Processing \& Management, Vol. 41, no 6: 1534-47.

Obermeier, U. and Brauckmann, H. 2010. Interdisciplinary patterns of a university: Investigating collaboration using co-publication network analysis. Collnet Journal of Scientometrics and Information Management, Vol. 4, no. 1: 29-40.

Park, S. Y. and Chung, E.K. 2013. Examining on the relationship between interdisciplinarity and research impact with analyzing the journals of library and information science field. Journal of the Korean Society for Information Management, Vol. 30, no 4: 7-29.

Pfirman, S. and Martin, P.J. 2010. Oxford handbook on interdisciplinarity.

Schummer, J. 2004. Multidisciplinarity, interdisciplinarity, and patterns of research collaboration in nanoscience and nanotechnology. Scientometrics, Vol. 59, no 3: 425-65.

Shannon, C.E. and Weaver, W. 1949. The mathematical theory of communication (Urbana, IL: University of Illinois Press IL.

Steele, T.W. and Stier, J.C. 2000. The impact of interdisciplinary research in the environmental sciences: A forestry case study. Journal of the American Society for Information Science, Vol. 51, no 5: 476-84.

Strader, C.R. 2009. Author-assigned keywords versus library of congress subject headings. Library Resources \& Technical Services, Vol. 53, no 4: 243-50.

Sugimoto, C. 2009. Proposal and application of the interdisciplinarity borrowing index: Determining the degrees of interdisciplinarity of ILS dissertations. Proceedings of the American Society for Information Science and Technology, Vol. 46, no 1: 1-6.

Taghva, K., Borsack, J., Nartker, T. and Condit, A. 2004. The role of manually-assigned keywords in query expansion. Information Processing \& Management, Vol. 40, no 3 : 441-58.

Tang, R. 2004. Evolution of the interdisciplinary characteristics of information and library science. Proceedings of the American Society for Information Science and Technology, Vol. 41, no 1: 54-63.

Wang, L., Notten, A. and Surpatean, A. 2013. Interdisciplinarity of nano research fields: A keyword mining approach. Scientometrics, Vol. 94, no 3: 877-92.

Weijing, C. and Ying, Z. 2013. Mining potential cooperative relationships based on the author keyword coupling analysis. Journal of Intelligence, Vol. 32, no 5: 127-31. 